Bangl. J. Vet. Med. (2007). 5 (1 \& 2): 77-80

\title{
CAUDAL EPIDURAL ANALGESIA IN SHEEP BY USING LIGNOCAINE HYDROCHLORIDE AND BUPIVACAINE HYDROCHLORIDE
}

\author{
N. S. Lucky, M. A. Hashim, J. U. Ahmed, K. Sarker, N. M. Gazi and S. Ahmed
}

Department of Surgery and Obstetrics, Faculty of Veterinary Science, Bangladesh Agricultural University, Mymensingh-2202, Bangladesh.

*Corresponding author’s e-mail address: luckymaria12@yahoo.com

\section{ABSTRACT}

The present investigation was conducted to find out the effect of different analgesic drugs in sheep. A series of 30 analgesic trials (caudal epidural analgesia) were conducted in sheep with $2 \%$ lignocaine hydrochloride (LH), $2 \%$ lignocaine hydrochloride with adrenaline (LHA) and 0.5\% bupivacaine hydrochloride (BH) in Veterinary Clinic, BAU, Mymensingh during January to April 2007. Analgesic injection was administered into low epidural space in 3 groups (A, B and C), each consisting of 10 apparently healthy sheep aged between 1 and 1.5 years. Effects of analgesic drugs on heart rate, respiration rate and rectal temperature were monitored. Heart rates significantly decreased but respiration rates decreased nonsignificantly and rectal temperature non significantly increased during low epidural analgesia with $0.5 \% \mathrm{BH}$. Heart rates and respiration rates increased significantly when $2 \%$ LH and 2\% LHA were used. LH (2\%) showed rapid spreading and was also free from any side effect. Duration of analgesia was prolonged with $2 \%$ LH compared to other analgesic drugs. Peak point of analgesia was more with $2 \%$ LHA as compare to other analgesic drugs. There was no significant difference between $0.5 \% \mathrm{BH}$ and $2 \% \mathrm{LHA}$ in terms of their analgesic effect. Drowsiness, tympany and shivering were observed when $0.5 \% \mathrm{BH}$ was used. It appears from the present study that $2 \%$ LH was more effective in low epidural analgesia.

Key words: Analgesia, peak point, low epidural, sheep

\section{INTRODUCTION}

Among the livestock population in Bangladesh sheep (2.47 million) occupies the third largest position (Anon., 2007). Among different types of local and regional analgesia, epidural analgesia has been used in veterinary practice for treatment of different surgical interferences e.g. amputation of tail, removal of udder, examination of rectum, uterus, vagina, abscess opening and operations. Majority of routine surgical procedures in ruminants can be done using local analgesics (Kumar and Chouhan, 1996). These techniques are simple, safe and economical and do not require sophisticated equipment. Besides this, general anaesthesia in this species often lead to tympanitis or regurgitation (Hashim and Hossain, 1989). Regurgitation is a hazard of anaesthesia in ruminants. Troncy et al. (2002) stated that use of epidural analgesia will depend on the medical problems of the patient, its temperament, the clinician's experience with epidural analgesia and the duration of surgical procedure. Theoretically, the technique may be used for any surgical procedure caudal to the diaphragm. Though a number of local analgesic agents are now available, lignocaine hydrochloride, bupivacaine hydrochloride are being mostly used for this purpose. Therefore, the present study was focused on to find out the analgesic effects, duration of action and clinical parameters of $2 \%$ lignocaine hydrochloride, $2 \%$ lignocaine hydrochloride with adrenaline and $0.5 \%$ bupivacaine hydrochloride in low (caudal) epidural analgesia in sheep.

\section{MATERIALS AND METHODS}

The research work was carried out in the Veterinary Clinic, Bangladesh Agricultural University, Mymensingh during January to April 2007. Thirty sheep of both sexes were taken from the herd of the Veterinary Clinic. Local analgesic trials were performed in 3 different groups (A, B and C). Each group comprised of 10 apparently healthy sheep of both sexes (body weight ranged from 10-20 kg and age ranged from 12-20 months) to investigate the effect of certain local analgesics in low (sacro-coceygeal) epidural analgesia during January to April 2007. 
Two percent lignocaine hydrochloride (Jasocaine ${ }^{\circledR}$, Jayson Pharmaceuticals Ltd., Bangladesh), 2\% lignocaine hydrochloride with $0.0005 \%$ adrenaline (Jasocaine- ${ }^{\circledR}$, Jayson Pharmaceuticals Ltd. Bangladesh), 0.5\% bupivacaine hydrochloride (Ultracaine ${ }^{\circledR}$, Jayson Pharmaceuticals Ltd. Bangladesh), at the dose rate 2.5 ml were administered in group A, B and C, respectively. The animals were maintained in a room at the Veterinary Clinic of the Bangladesh Agricultural University, Mymensingh. All animals were routinely dewormed and vaccinated against common infectious diseases. Age, sex and body weight were recorded and frequently examined to detect any pathological condition.

The animals were taken to the operation theatre 40-45 minutes prior to the administration of analgesics. The animal was placed on the operation table in lateral recumbency and was restrained physically by an assistant. The injection site (sacrococcygeal space) was clipped, shaved and was painted with tincture of iodine before any injection was given. No premedicant was given prior to analgesic injection. Care was taken not to excite the animal before and during monitoring. The respiration rate, pulse rate and rectal temperature were recorded. The state of analgesia was observed in every 3 minutes with the help of a needle by pricking the region. Peak point (time at which maximum area was desensitised) onset and duration of analgesia were recorded. The desensitized area was measured by a scale $(\mathrm{cm})$ and the progression of analgesia at every 3 minutes were recorded. The measurement was carried out up to recovery. Tail movement, leg movement and any side effects were closely observed and recorded during the course of analgesia.

Student's $t$-test was performed to compare the obtained data before and after analgesia. Analysis of variance (ANOVA) in completely randomized design was performed to find out significant variation among the effects in different groups of this experiment and LSD was also done for mean separation.

\section{RESULTS AND DISCUSSION}

\section{Clinical parameters}

In group $A$, respiration rates were significantly $(p<0.01)$ increased during analgesia as compared to preanalgesic values. After recovery, the mean values of heart and respiration rates were non significant as compared to preanalgesic values. The mean value of rectal temperature during and after analgesia was not significant (Table 1). In group $B$, the mean values of heart rate and respiration rate were significantly $(\mathrm{p}<0.01)$ increased as compared to preanalgesic values (Table 1).

Table 1. Effects of analgesic agents on the heart rate, respiration rate and rectal temperature during low epidural analgesia in sheep

\begin{tabular}{|c|c|c|c|c|c|c|c|c|c|}
\hline \multirow{2}{*}{$\begin{array}{l}\text { Groups } \\
(\mathrm{n}=10)\end{array}$} & \multicolumn{3}{|c|}{ Heart rate/min } & \multicolumn{3}{|c|}{ Respiration rate/min } & \multicolumn{3}{|c|}{ Rectal temperature $\left({ }^{0} \mathrm{~F}\right)$} \\
\hline & $\begin{array}{l}\text { Before } \\
\text { analgesia }\end{array}$ & $\begin{array}{l}\text { During } \\
\text { analgesia }\end{array}$ & $\begin{array}{l}\text { After } \\
\text { recovery }\end{array}$ & $\begin{array}{l}\text { Before } \\
\text { analgesia }\end{array}$ & $\begin{array}{l}\text { During } \\
\text { analgesia }\end{array}$ & $\begin{array}{l}\text { After } \\
\text { recovery }\end{array}$ & $\begin{array}{l}\text { Before } \\
\text { analgesia }\end{array}$ & $\begin{array}{l}\text { During } \\
\text { analgesia }\end{array}$ & $\begin{array}{l}\text { After } \\
\text { recovery }\end{array}$ \\
\hline \multirow[t]{3}{*}{ A (LH) } & 96.40 & 102.80 & 95.00 & 30.60 & 38.00 & 30.60 & 102.23 & 102.25 & 102.25 \\
\hline & \pm & \pm & \pm & \pm & \pm & \pm & \pm & \pm & \pm \\
\hline & 6.58 & $6.40 *$ & 3.21 & 2.02 & $2.95^{* *}$ & 2.44 & 0.18 & 10.18 & 0.19 \\
\hline \multirow{3}{*}{ B (LHA) } & 96.60 & 106.30 & 100.90 & 35.60 & 40.10 & 36.70 & 102.67 & 102.65 & 102.61 \\
\hline & & & & & & & & & \\
\hline & 4.72 & $4.24^{* *}$ & 3.21 & 2.50 & $2.50 * *$ & 1.52 & 0.23 & 0.21 & 0.20 \\
\hline \multirow[t]{3}{*}{$\mathrm{C}(\mathrm{BH})$} & 96.80 & 91.40 & 88.90 & 31.60 & 30.00 & 30.20 & 102.23 & 102.47 & 102. 48 \\
\hline & \pm & \pm & \pm & \pm & \pm & & \pm & \pm & \\
\hline & 4.41 & 5.12 & $3.48^{* *}$ & 2.36 & 2.30 & 2.18 & 0.22 & 0.14 & 0.14 \\
\hline
\end{tabular}

LH- Lignocaine hydrochloride, LHA- Lignocaine hydrochloride with adrenaline, BH- Bupivacaine hydrochloride, **Significant at $\mathrm{p}<0.01$, *Significant at $\mathrm{p}<0.05, \mathrm{n}=$ Number of experimental sheep.

In group $\mathrm{C}$, the mean values of heart rate and respiration rate decreased non significantly during analgesia but temperature increased and after recovery the mean values of heart rate, decreased significantly $(\mathrm{p}<0.01$ ), respiration rates decreased non significantly but temperature increased non significantly as compared to preanalgesic values (Table 1). 
The effect of local analgesic on clinical parameters during epidural analgesia results from both local and systemic absorption (Lumb and Jones, 1984). DeRossi et al. (2005) found, heart and respiratory rates and blood pressure remained unchanged after lignocaine induced analgesia. Xylazine lidocaine caused significant decreases in the heart and respiratory rates but not in blood pressure (Beretta, 2005). During lignocaine induced analgesia mean heart rates were significantly higher and respiratory rates and rectal temperature were significantly low (Nweke, 2004).

Bupivacaine hydrochloride $0.5 \%$ decreased heart and respiration rate insignificantly in low epidural analgesia which is in agreement with the previous report (Kinjardekar and Pratap, 2002), though Gill et al. (1984) observed no variation in heart rate, respiration rate and rectal temperature using $0.5 \%$ bupivacaine hydrochloride in low epidural analgesia. Decreased respiration rate might result form their depressing action on respiratory center in central nervous system through general circulation (Hall and Clarke, 1989). In this study the rectal temperature in sheep of group A and C increased insignificantly but decreased in group B.

\section{The peak point of analgesia}

Analgesia reached peak point within 10-20 minutes in all animals of group A and within 11-24 minute in group $B$. In group $C$ the analgesic agent exerted its maximum effect within 6-22 minutes in all animals. There was no significant difference between group A and C but in group B the difference was statistically significant $(\mathrm{p}<0.01)$ (Table 2).

The time (the peak time of analgesia) at which maximum area was blocked and the progression of analgesia (at peak time of analgesia) were recorded to explain the extent of blockade of analgesic agents. The peak time of analgesia was short with $2 \% \mathrm{LH}$. The physical characteristics of the animals governed the distribution of injected drugs in the epidural space e.g. body weight, length of the back of the animal, size of spinal canal, amount of epidural fat (Lee, 2006).

\section{The extent of analgesia (area of desensitisation)}

The extent of analgesia was high with $2 \%$ LH among different local analgesic agents used in sheep in this study. This observation supports the previous findings (DeRossi et al., 2005). Though the influence of vascular absorption has been ignored, it is well established that the veins composing venous plexous are relatively large and provide a large vascular surface for rapid vascular absorption (Dyce et al., 1996). There was no significant difference between group B and C while group A differed significantly $(\mathrm{p}<0.01)$ (Table 2).

Table 2. Effects of various analgesic drugs during low epidural analgesia in sheep

\begin{tabular}{|l|l|l|l|l|l|}
\hline Groups & $\begin{array}{l}\text { Amount of } \\
\text { drugs }(\mathrm{ml})\end{array}$ & $\begin{array}{l}\text { Body wt. of animal } \\
(\mathrm{kg})(\text { Mean } \pm \text { SD) }\end{array}$ & $\begin{array}{l}\text { Peak point of } \\
\text { analgesia (min) } \\
(\text { Mean } \pm \text { SD) }\end{array}$ & $\begin{array}{l}\text { Duration (min) } \\
(\text { Mean } \pm \text { SD) }\end{array}$ & $\begin{array}{l}\text { Desensitised area at } \\
\text { peak point }(\mathrm{cm}) \\
(\text { Mean } \pm \text { SD) }\end{array}$ \\
\hline A (LH) & 2.5 & $14.8 \pm 2.48^{\mathrm{a}}$ & $\begin{array}{l}10-20 \\
14.1 \pm 3.87^{\mathrm{b}}\end{array}$ & $\begin{array}{l}19-41 \\
33.8 \pm 8.75^{\mathrm{a}}\end{array}$ & $12.07 \pm 3.61^{\mathrm{a}}$ \\
\hline B (LHA) & 2.5 & $14.8 \pm 2.48^{\mathrm{a}}$ & $\begin{array}{l}11-24 \\
17.9 \pm 5.11^{\mathrm{a}}\end{array}$ & $\begin{array}{l}19-41 \\
30.2 \pm 8.04^{\mathrm{b}}\end{array}$ & $10.2 \pm 2.73^{\mathrm{b}}$ \\
\hline C (BH) & 2.5 & $14.8 \pm 2.48^{\mathrm{a}}$ & $\begin{array}{l}6-22 \\
13.3 \pm 5.29^{\mathrm{b}}\end{array}$ & $\begin{array}{l}12-40 \\
30 \pm 9.19^{\mathrm{b}}\end{array}$ & $10.67 \pm 3.64^{\mathrm{b}}$ \\
\hline Level of significance & NS & $* *$ & $* *$ & $* *$ \\
\hline
\end{tabular}

LH- lignocaine hydrochloride, LHA- Lignocaine hydrochloride with adrenaline, BH- Bupivacaine hydrochloride, **Significant at $\mathrm{p}<0.01$, The values with different superscripts within the same column differed significantly at $\mathrm{p}<0.01$.

\section{The duration of analgesia}

The duration of analgesia with $2 \% \mathrm{LH}$ was longer than $0.5 \% \mathrm{BH}$. Lignocaine has intermediate duration of action. This observation corresponds with the findings of Lemke and Dawson (2000). This effect can be ignored as lignocaine has short latency period (Covino, 1986). Same amount of analgesic drugs in low epidural analgesia showed different effects i.e. peak time of analgesia, extent of analgesia from the site of injection at peak point and duration of analgesia were different when timing was considered. The findings were supported by Adetunji et al. (2002). 


\section{Other observations}

The side effects found mostly in C. These effects were tympany, shivering, drowsiness, muscle tremor especially when bupivacaine hydrochloride was used. No fatality was observed throughout this experiment. These findings are supported by Laishley et al. (1988). These side effects were not always observed in all animals. Nweke (2004) found notable side effect was salivation in all experimental animals.

Lignocaine hydrochloride produced prolonged epidural analgesia as compared to BH. Extent of epidural blockade was more with $2 \%$ LH where as peak point of analgesia was more with $2 \%$ LHA. Incorporation of adrenaline with local analgesic does not appear to prolong the analgesic duration and also recommended that lignocaine has a long duration of action in sheep. If a longer time is required for surgery with low epidural analgesia, $2 \%$ LH may be used.

\section{REFERENCES}

1. Adetunji A, Ajadi RA and Opia RE (2002). A comparison of epidural anaesthesia with xylazine, bupivacaine and bupivacaine/xylazine mixture in West African dwarf goats. Nigerian Veterinary Journal 20: 67-69.

2. Anon. 2007. Statistics of livestock. Department of Livestock Service, Ministry of Livestock and Fisheries, Government of Bangladesh.

3. Beretta MP (2005). Analgesic and systemic effects of xylazine, lidocaine and their combination after subarachnoid administration in goats. Journal of African Veterinary Association 76: 79-84.

4. Covino BG (1986). Pharmacology of local anaesthetic agents. British Journal of Anaesthesia 58: 701-706.

5. DeRossi R, Junqueira AL and Beretta MP (2005). Analgesic and systemic effects of xylazine, lidocaine and their combination after subarachnoid administration in goats. Journal of African Veterinary Association 76: 79-84.

6. Dyce KM, Sack WO and Wensing CJ (1996). Text book of Veterinary Anatomy. $2^{\text {nd }}$ edn., Saunders, Philadelohia, USA, pp. 259-324.

7. Gill SS, Pandey SK and Chjandrapuria VP (1984). Bupivacaine HCL as epidural anaesthetic in cattle. Indian Veterinary Journal 61: 758-761.

8. Hall LW and Clarke KW (1989). Veterinary Anaesthesia. $8^{\text {th }}$ edn., Bailiere Tindal, London, pp. 47-52.

9. Hashim MA and Hossain MA (1989). Effect of starvation and positioning on gastro-esophageal reflux in anaesthetized goat during chloral hydrate-magnesium sulphate anaesthesia. Bangladesh Journal of Scientific and Industrial Research 24: 62-69.

10. Kinjardekar P and Pratap K (2002). Comparison of ketamine and xylazine for lumbo-sacral epidural analgesia in buffalo calves. Indian Journal of Veterinary Surgery 21: 117.

11. Kumar A and Chouhan DS (1996). Local anaesthesia. In: Ruminant Surgery. $1^{\text {st }}$ edn., Tyagi RPS and Singh J (eds.), CBS, Shahdara, Delhi. p. 110.

12. Laishley RS, Morgan BM and Reynolds F (1988). Effect of bupivacaine on extradural anaesthesia. British Journal of Anaesthesia 60: 180-186.

13. Lee L (2006). Local analgesia and anaesthesia. Center for Veterinary Health Sciences, Oklahoma State University pp. 25-30.

14. Lemke KA and Dawson SD (2000). Local and regional anesthesia. Veterinary Clinics of North American Small Animal Practices 30: 839-57.

15. Lumb WV and Jones EW (1984). Veterinary Anaesthesia. $2^{\text {nd }}$ edn., Lea and Febiger, Philadelphia, p. 580.

16. Nweke RI (2004). Comparison of physiologic and analgesic effects of xylazine/ketamine, xylazine/lignocaine, and lignocaine anaesthesia in West-African Dwarf Goat. Nigerian Veterinary Journal 25: 41-43.

17. Troncy E, Junot S, Keroack ST and Sammut V (2002). Results of primitive epidural administration of morphine with or without bupivacaine in dogs and cats undergoning surgery. Journal of American Veterinary Medical Association 221 (5): 666-672. 